\title{
SUPPLY QUALITY IMPROVEMENT USING SERIES COMPENSATOR
}

\author{
H. Z. Azazi A. El-Sabbe S. S. Shokralla and S. A. Mahmoud \\ Electrical Engineering Department, Faculty of Engineering, \\ Minoufiya University, Shebin El-Kom, Egypt
}

\begin{abstract}
This paper introduces a variable capacitive reactance for compensation using a series controlled capacitor for load voltage stabilization. Employing capacitors is the simplest method of reducing the effective impedance the line. The proposed system operates for load voltage stabilizing with static or dynamic load. This system improves input power factor and reduces the input line current harmonic. The proposed system is used also for mitigation of voltage sag. Simulation and experimental results are obtained for open and closed loop voltage control system. The integral proportional (PI) controller is used to control the load voltage by controlling the capacitor effect. The effectiveness of the proposed method is verified through simulation and experimental results.

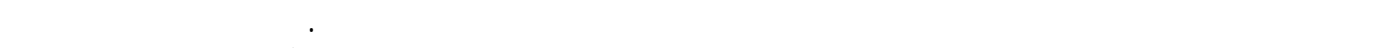

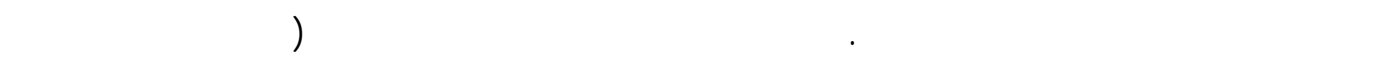

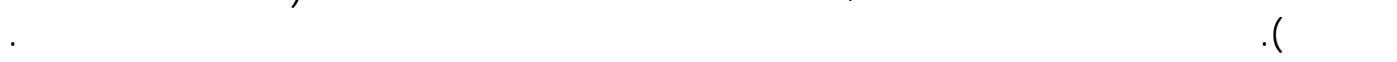

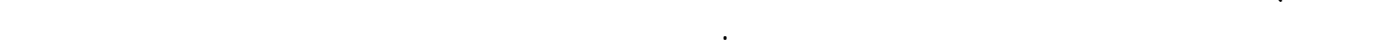

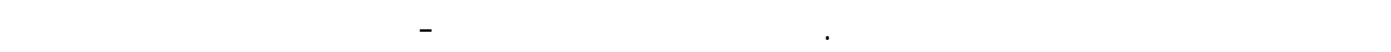

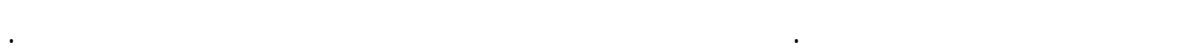

Keywords: Load voltage, series compensation, Voltage sag

\section{INTRODUCTION}

The recent developed of semiconductor device technology realizes small size, light-Wight, and high performance power switching device. But reactive elements such as an inductor or capacitor are still physically large and heavy. If a compact and high efficient reactive component is developed, the power converter technology may drastically change the application field [1-2].

The series controlled capacitor consists of an inverter and capacitor; this system can produce larger value of a reactance than actually used, the value of the virtual reactance can be varied [3].Using controlled capacitor and/or inductor can generate not only positive inductance which exists naturally, but can also produce negative reactance that cancels undesired inductance including in transient state of the system. Negative inductance can decrease the circuit impedance without any additional resonance [4].

Use of capacitors is the simplest method of reducing the effective impedance of a line. Control is affected by switching capacitors into or out of load circuit. Use of series capacitors calls for special protection schemes and may caused instabilities due to the formation of resonant circuits in combination with inductances naturally present in a network [5].

In order to improve the supply quality and power factor, controlled capacitor used in series with inductive load (static or dynamic). In this paper a variable reactance type series compensation by using a series controlled capacitor is proposed to operate as an ac voltage controller for controlling the load voltage, without any discontinuity in the supply current, also it can operate as a boost ac chopper, when the capacitor reactance is greater than the circuit inductive reactance. Using controlled capacitor in the proposed system improves the supply quality and the transient performance of the dynamic loads [6].

A voltage sag is a reduction between 10 and $90 \%$ in root-mean-square voltage, with a duration between 0.5 cycles and $1 \mathrm{~min}$. It is generally caused by a short circuit or overload in the utility system, also, due to starting of heavy induction motors. Typically, voltage sag duration ranges from 0.5 to 30 cycles, and its depth depends on the power system distribution and the approximatly to the fault site [7]. Adjustable-speed drives (ASDs) are one of the most sensitive loads to voltage sags because transient voltages cause nuisance tripping events [8]. The mitigation of voltage sag is introduces in many paper [9-11].

In this paper the propoesd system with insertion technique is used for mitigation of voltage sag, also the load voltage can be stabilized over a wide range taking the supply impedance into account

\section{SYSTEM DESCRIPTION}

The proposed system of series controlled capacitor for load voltage stabilization is shown in Figure (1). 
In this system, the supply impedance is taken into account, and the load may be inductive (static or dynamic).

Series controlled capacitor is used to decrease the effect of load and supply inductances, without any discontinuity in the supply current. The effective value of the capacitor can be controlled from zero to maximum value through four IGBT's. Analog drive circuit is built to generate two groups of pulses for controlling the IGBT's, where each pair of IGBT's is switched alternatively. Control voltage will control the duty cycle of pulses to control the capacitor current.

The system can be operate at lagging power factor $\left(\mathrm{x}_{\mathrm{t}}>\mathrm{x}_{\mathrm{c}}\right)$, with low duty ratio, or at leading power factor $\left(\mathrm{x}_{\mathrm{t}}<\mathrm{x}_{\mathrm{c}}\right)$, with high duty ratio.

Where, $X_{t}$ is the total equivalent series inductance of the load and supply.

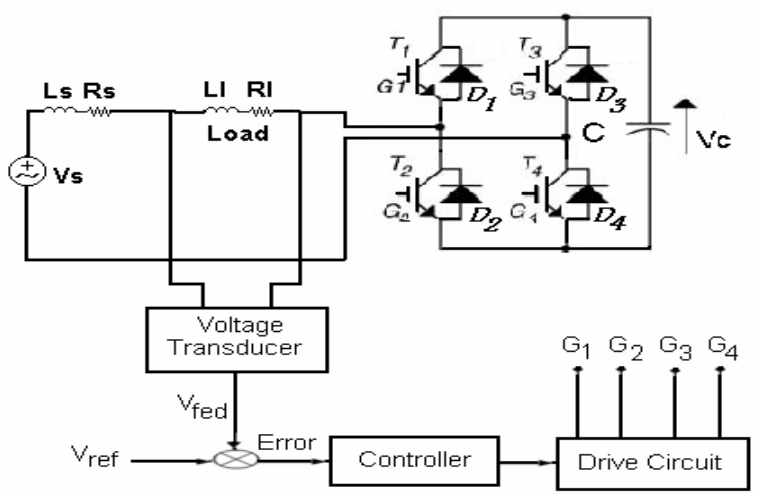

Figure (1) The proposed system for load voltage stabilization

\section{SYSTEM MODELING}

Considering R-L load, the drive circuit generates two groups of pulses, where each pair of IGBT's is switched alternatively. During positive half cycle, the switches $\left(\mathrm{T}_{2}, \mathrm{~T}_{3}\right)$ are forward biased and switches $\left(\mathrm{T}_{1}, \mathrm{~T}_{4}\right)$ are reveres biased. Differential equations for each mode of operation (in positive half cycle) can be written as follows:

\subsection{Mode (1)}

In this mode, when switches $\left(\mathrm{T}_{2}, \mathrm{~T}_{3}\right)$ are turned on. The current flows taking the path shown in Figure (2), and the capacitor $\mathrm{C}$ is connected to the line circuit where the capacitor will be charging. The corresponding differential equations describing this mode are;

$V_{s}=i \cdot R_{t}+L_{t} \cdot \frac{d i}{d t}+V_{c}$

$V_{c}=\frac{1}{c} \cdot \int i \cdot d t$

\subsection{Mode (2)}

This mode starts when the switches $\left(T_{2}, T_{3}\right)$ are off. The current will be following in the same direction as in mode (1) because the inductance of the circuit, so the current will be passes in the two diodes $\left(D_{1}, D_{4}\right)$. So the polarity of the capacitor will be reversed, and the capacitor voltage will be discharged. The current flows taking the path shown in figure (3). The corresponding differential equations describing this mode are as follows:

$V_{s}=i \cdot R_{t}+L_{t} \cdot(d i / d t)-V_{c}$

During negative half cycle, the same two modes which shown above are repeated but through $\mathrm{T}_{1}, \mathrm{~T}_{4}$ (charging), and $\mathrm{D}_{2}, \mathrm{D}_{3}$ discharging.

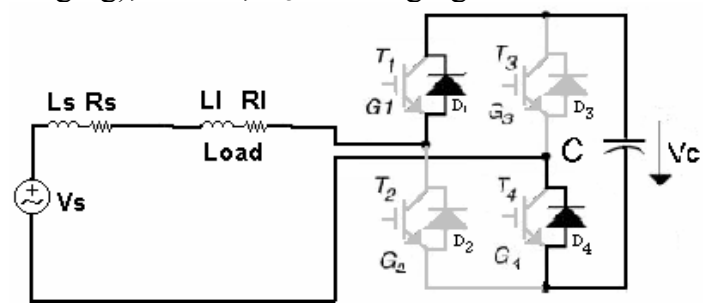

Figure (2) Equivalent circuit of mode 1of operation during positive half cycle

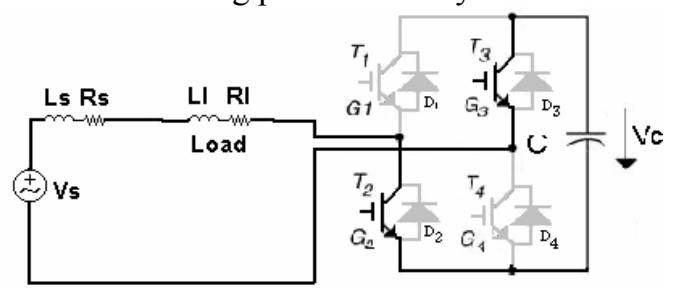

Figure (3) Equivalent circuit of mode 2 of operation during positive half

\section{CLOSED LOOP LOAD VOLTAGE CONTROL}

The load voltage is affected by switching capacitor into or out of load circuit. The closed loop with PI controller is used for stabilizing the load voltage as shown by block diagram in figure (4).

The feed back voltage is compared with the reference voltage. Error is fed to the integral unit to give signal $\mathrm{U}$ that compared with the same feed back voltage, the result signal is fed to the proportional unit. The control voltage is responsible for changing the duty ratio of switches operation to control the capacitor value that stabilizes the load voltage at the value corresponds to the reference voltage. The controller equation can be written as:

$$
\begin{aligned}
& \tau_{1} \cdot(d u / d t)=V_{r e f}-K_{v} \cdot V_{L} \\
& V_{c}=K_{1}\left(U-K_{v} \cdot V_{L}\right)
\end{aligned}
$$

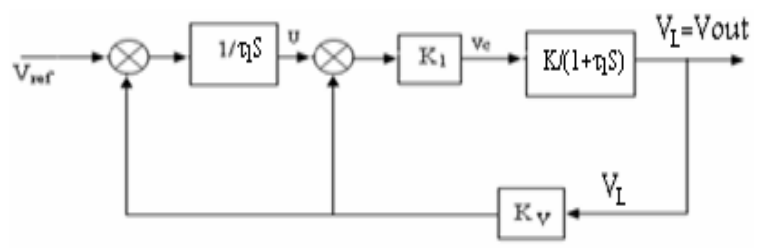

Figure (4) PI Controller Block Diagram 


\section{SIMULATION AND EXPERIMENTAL RESULTS}

The results of the proposed system with static load are taken for open and closed loop. The simulation results of the system for open and closed loop are obtained using MATLAB software. Experimental results of the system for open and closed loop are obtained using a laboratory set-up of the proposed system (Appendix), where analogue circuits of PI controller and drive circuit of the switches are built and tested.

\subsection{Open Loop System}

Figure (5) shows the simulation and experimental waveforms of the supply voltage and current at $\mathrm{VS}=60$ volt and duty ratio $=75 \%$. It is noticed that the supply current is nearly sinusoidal without any discontinuity. Changing the duty ratio of the switches operation will change the current waveforms.

Figure (6) shows the simulation and experimental waveforms of the load voltage at $\mathrm{VS}=60$ volt and duty ratio $=75 \%$.

Figure (7) shows the relation between duty ratio and the input power factor. It is clear that, increasing the duty ratio increases the input power factor.

\subsection{Closed-Loop System with (PI) Voltage Controller}

Figure (8) shows the simulation and experimental results of load voltage due to $+25 \%$ change in reference voltage. It is clear that, the load voltage follows the desired reference voltage.

Figure (9) shows the simulation and experimental results of load voltage and load current due to $15 \%$ step change in the load. It is noticed that, during step change in the load by increasing or decreasing the load current within certain limits $+15 \%$ of the full load value, the proposed system will keep the load voltage constant as shown in figure (9).

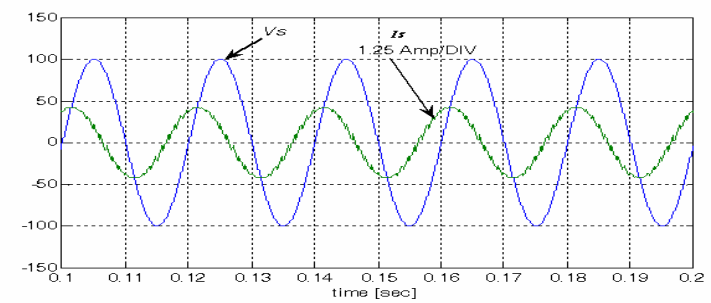

(a) Simulation

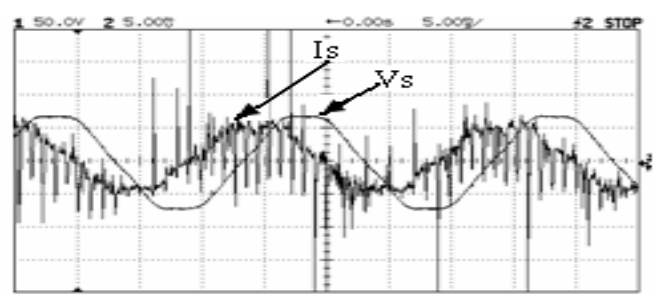

(b) Experimental

Figure (5) Simulation and experimental results of supply voltage and current at $\mathrm{V}_{\mathrm{S}}=60$ Volt and duty ratio $=75 \%$

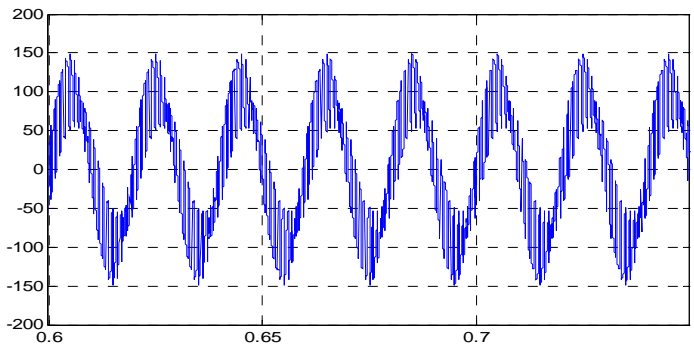

(a)Simulation

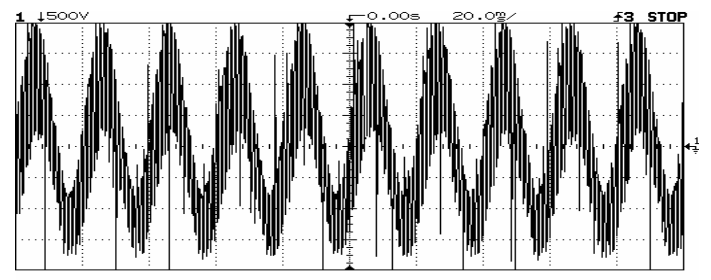

(b) Experimental

Figure (6) simulation and experimental results of load voltage at $\mathrm{V}_{\mathrm{S}}=60$ Volt and duty ratio $=75 \%$

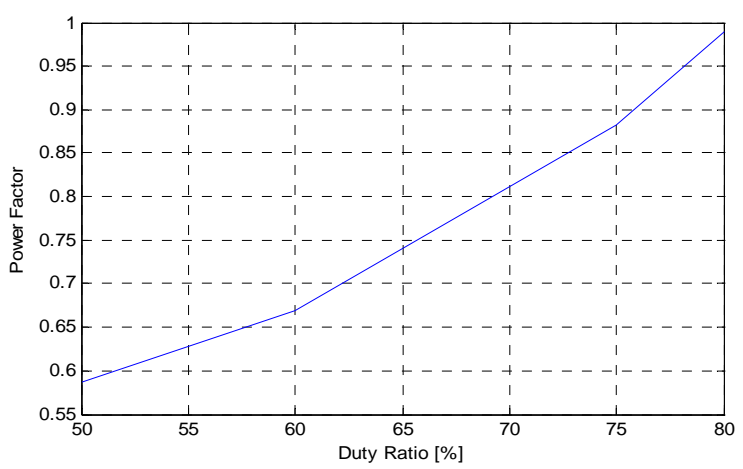

Figure (7) The relation between duty ratio and the input power factor

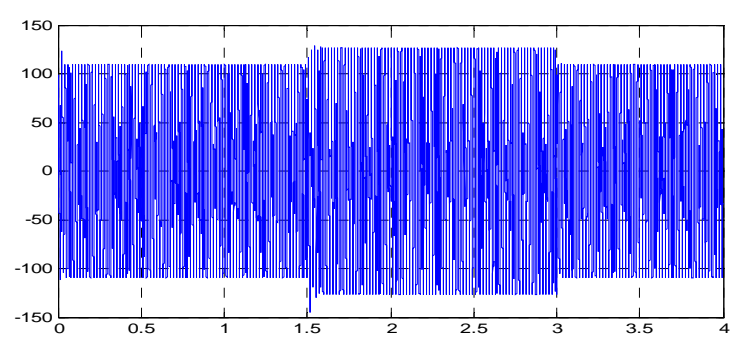

(a) Simulation

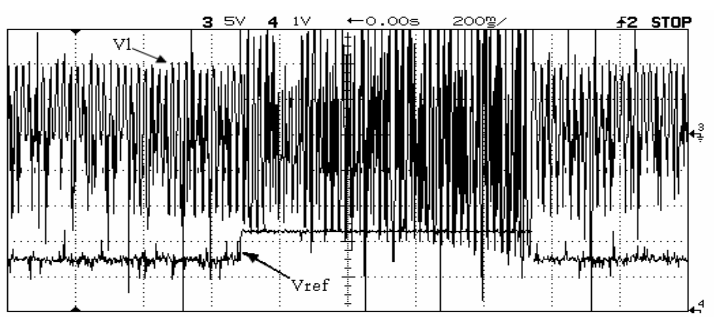

(b) Experimental

Figure (8) Simulation and Experimental results of load voltage due to $+25 \%$ change in reference voltage 

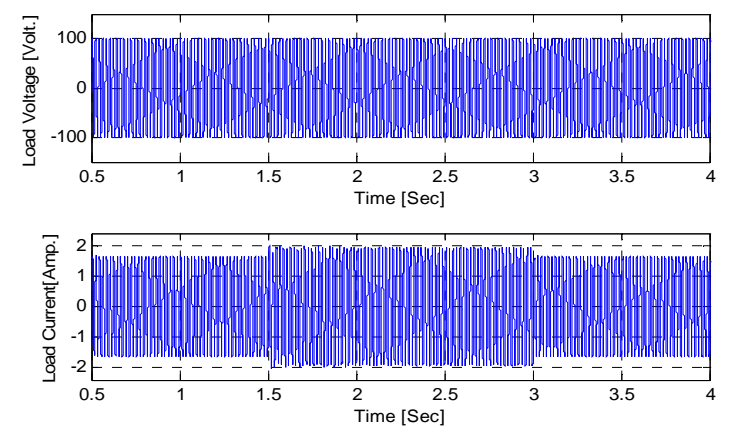

(a) Simulation

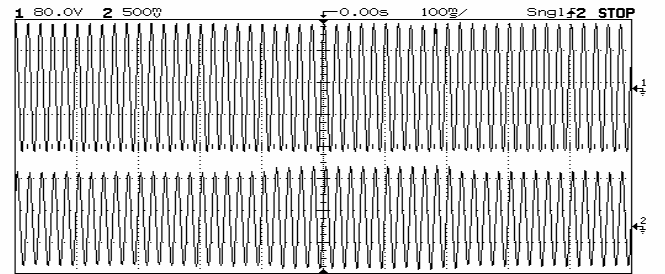

(b) Experimental

Figure (9) simulation and experimental results of load voltage and load current due to $+15 \%$ step change in the load

\section{VOLTAGE SAG MITIGATION}

Voltage sag is one of the main power quality problems faced by many industrial customers. It is a reduction between 10 and $90 \%$ in root-mean-square voltage, with a duration between 0.5 cycles and 1 minute that may be accompanied with phase jumps and are caused by faults on the power system or starting large loads, such as motors. Equipment used in modern industrial plants (process controllers, programmable logic controllers, adjustable speed drives, and robotics) is becoming more sensitive to voltage sag due to the increased complexity of the equipment. Voltage sag causes sensitive equipment to trip and this can result in considerable financial losses experienced by the industrial customers.

There are different techniques to overcome voltage sag such that; Tap Changers ; Thyristor-Controlled Reactor (TCR); Thyristor-Switched Capacitor (TSC); Dynamic Voltage Restorer (DVR) [12-16].

The proposed system shown in Figure (10) is used for voltage sag mitigation. The load is ac motor in system 1 .The load voltage is changed by changing the injected voltage by controlling the duty ratio of the switches in system 2 , so the load voltage can be kept at constant value, where the duty ratio is employed to vary the equivalent reactance seen by the transmission line at the transformer primary winding. Prototype had been built and tested to check the idea of voltage sag mitigation.

\subsection{Run-Up Characteristics}

Figure (11) shows the experimental results for the load voltage and current during Run-up without insertion, but Figure (12) shows the experimental results for the load voltage and current during Runup with insertion. It is noticed that, in figure (11) there is a voltage dip in load voltage during starting due to the large starting current of the motor; but in Figure (12) the load voltage and current are constant during the starting due to using the proposed technique of insertion from system 2 .

Note, the scale in figure (11) is increased by percentage $1: 10$ by using resistance.

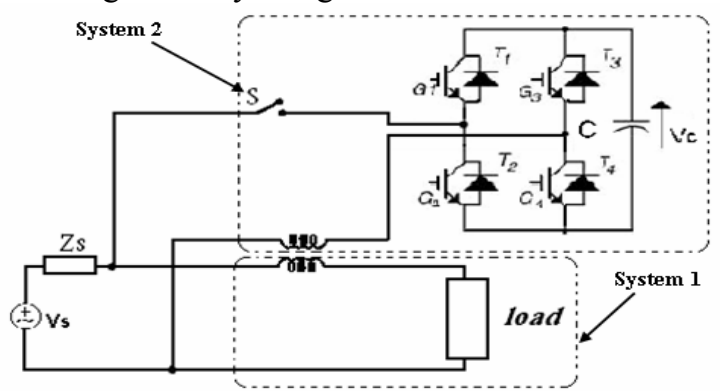

Figure (10) The proposed system for voltage sag

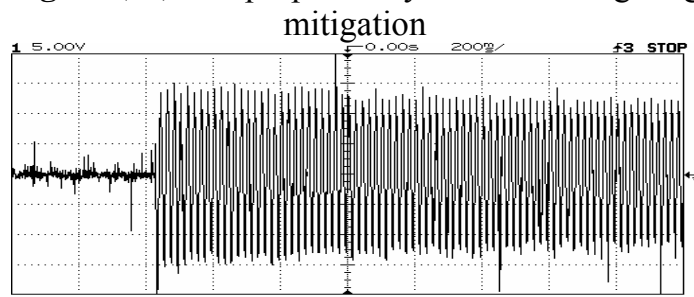

(a) Load voltage

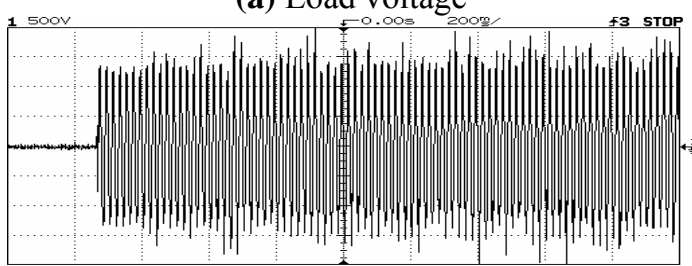

(b) Load current

Figure (11) load voltage and current during Run-up without insertion

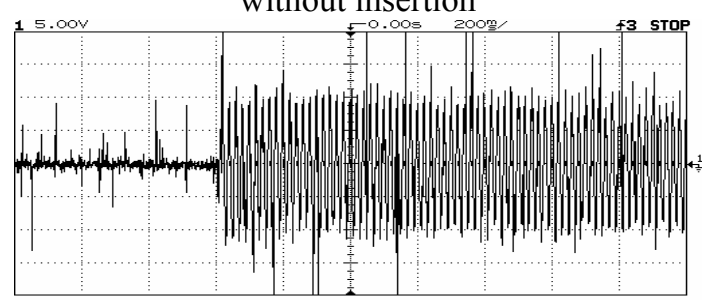

(a) Load voltage

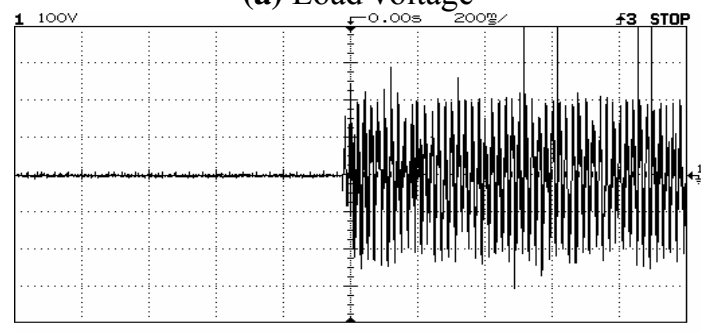

(b) Load current

Figure (12) load voltage and current during Run-up with insertion 


\subsection{Steady-State Characteristics}

Figures (13) and (14) show the experimental waveforms of load voltage and current with and without insertion during steady-state. It is noticed that the load voltage and current are approximately sinusoidal due to synchronization between the voltages in the two systems.

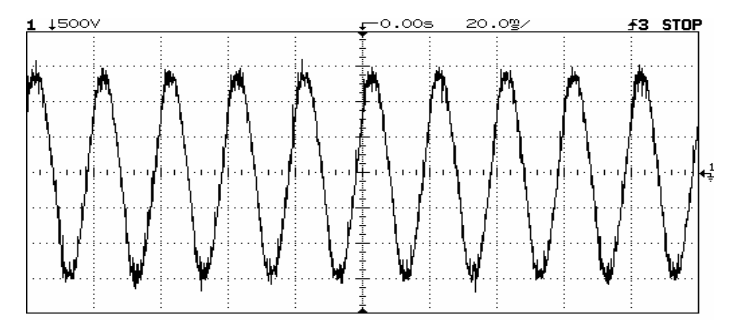

(a) Load voltage

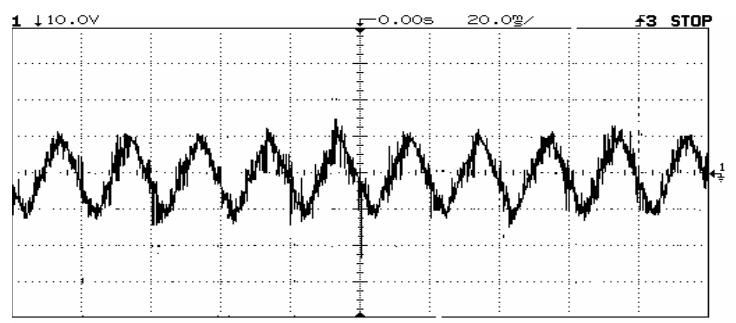

(b) Load current

Figure (13) Experimental steady state load voltage and current without insertion
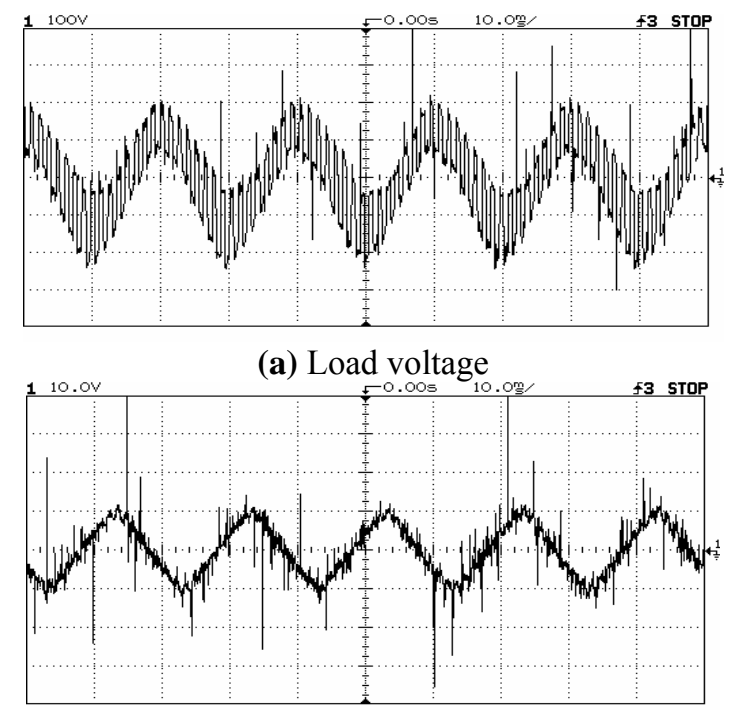

(b) Load current

Figure (14) Experimental steady state load voltage and current with insertion

\subsection{Load Disturbance}

Figure (15) shows the experimental results for the load voltage and current during positive change in load without insertion. Figure (16) shows the experimental results for the load voltage and current during positive change in load with insertion.It is noticed that for the system without insertion, the load voltage is decreased and load current is increased and take long time about $1.2 \mathrm{sec}$ to reach the steady state value. The load voltage for the proposed system with insertion is constant and the current is increased and take minimum time for reach the steady state value.

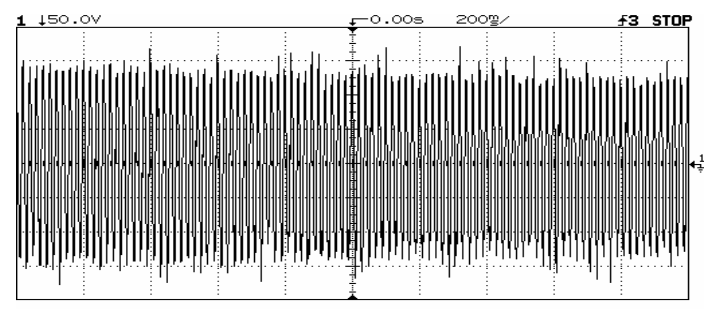

(a) Load voltage

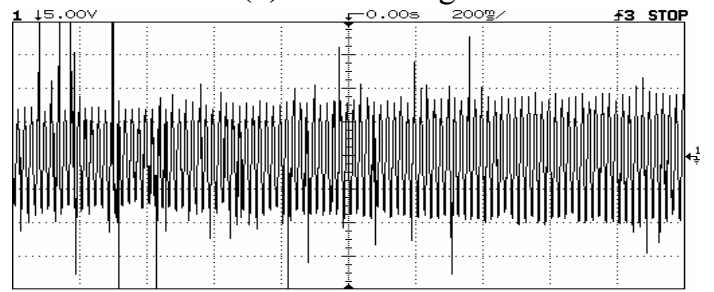

(b) Load current

Figure (15) Experimental load voltage and current during load disturbance without insertion

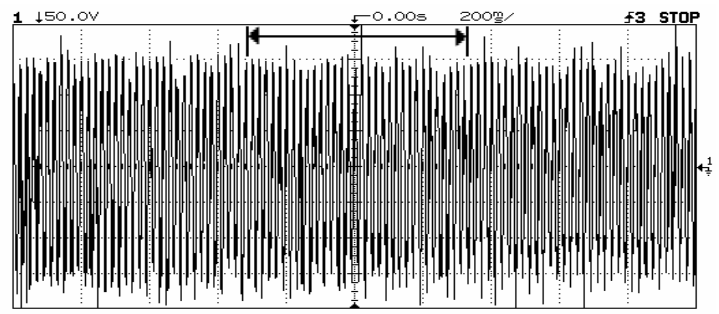

(a) Load voltage

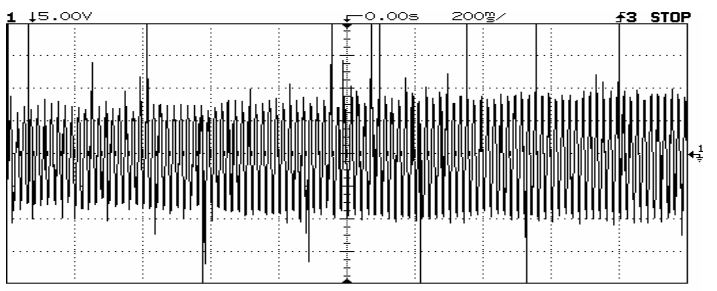

(b) Load current

Figure (16) Experimental load voltage and current during load disturbance with insertion

\section{CONCULUSION}

The proposed system uses controlled capacitor as a series compensator to improve the input power factor. With PI controller the system operates as a voltage controller to regulate the load voltage without discontinuity of the supply current. The capacitor value affects the system performance when the capacitor value is greater than the total system reactance, the proposed system operates as a boost volatge regulator. 
The system can also be used as a series compensation for voltage sag mitigation. The injection voltage can be changed by changing the duty ratio, the load voltage can be kept at a constant value at starting and at load disturbance.

The simulation results for both open and closed loop voltage control are given and proved to yield good agreement when compared with the experimental results.

\section{REFERENCES}

[1] H. Akagi, Y. Kanazawa, and A. Nabae, "Instantaneous Reactive Power Compensator Comprising Device Without Energy Storage Components" IEEE Trans. On Ind. Appl. Vol. 20,No.22, PP. 625-630, 1984.

[2] H. Funato and A. Kawamura, "Proposal of Variable Active-Passive Reactance," International Conference on Industrial Electronics, Control, Instrumentation and Automation (IECON'92), San Diego, USA, pp. 381-388, Nov. 1992.

[3] H. funato and A. kawamura, "Analysis of Variable Active-Passive Reactance" power Conversion Conference (PPC). Yokohama, in Yokohama, Japan. pp 647-652, Apr. 1993.

[4] Hirohito Funato, Atsuo Kawamura and Kenzo Kamiyama," Realization of Negative Inductance Using Variable Active-Passive Reactance (VAPAR)", IEEE Trans. On Power Electronics, Vol. 12, No. 4, PP. 589-596, July 1997.

[5] D. A. James and W. T. Norris, "Series Compensation Using Power Electronic Switches," sixth international conference on (conf.pub.No.423), AC and DC power transmission, IEE CNF, pp.405-410, 29 apr-3 may 1996.

[6] A. EL-Sabbe, "Load Voltage Stabilization Based On the Series Compensation" Eng. Research Journal, Minufiya University. Faculty of Eng., Egypt, Vol.25, No.4, PP.135-144, 2002

[7] M. H. J. Bollen, "Understanding Power Quality Problems: Voltage Sags and Interruptions. New York: McGraw-Hill, , pp. 18, 174-198, 1996.

[8] J. Pedra, F. Córcoles and F. J. Suelves" Effects of Balanced and Unbalanced Voltage Sags on VSIFed Adjustable-Speed Drives," IEEE Trans on power delivery, Vol. 20, No. 1, January 2005

[9] Khaled Tag eddeen, Hussein M. Mashaly and Ahmad M. A. Mahmoud "Performance of Dynamic Voltage Restorer For Voltage Sag Mitigation, "The Tenth International Middle East Power Systems Conference, Port Said, Egypt, Dec.13-15,2005
[10] S. S. Choi, J. D. Li and D. Mahinda Vilathgamuwa "A Generalized Voltage Compensation Strategy for Mitigating the Impact of Voltage Sags/Swells," IEEE Transaction ON Power Delivery, Vol. 20, No.3.July 2005

[11] Yun Wei Li, D. Mahinda Vilathgamuwa and Poh Chiang Loh "A Grid-Interfacing Power Quality Compensator for Three-Phase ThreeWire Microgrid Applications," IEEE Trans. on power electron, Vol. 21, No. 4, JULY 2006

[12] H. Awad, J. Svensson, and M. Bollen, "Mitigation of Unbalanced Voltage Dips Using Static Series Compensator," IEEE Trans. Power Electron., vol. 19, no. 3, pp. 837-846, May 2004.

[13] Bingsen Wang, Giri Venkataramanan, and Mahesh Illindala," Operation and Control of a Dynamic Voltage Restorer Using Transformer Coupled H-Bridge Converters," IEEE Trans. on power electron, Vol. 21, No. 4, JULY 2006

[14] M.R. Banaei, S.H. Hosseini and G.B. Gharehpetian," Inter-Line Dynamic Voltage Restorer Control Using a Novel Optimum Energy Consumption Strategy," M.R. Banaei et al. / Simulation Modelling Practice and Theory, Vol. 14, pp. 989-999, 2006

[15] S. M. Bashi, "Microcontroller-Based Fast OnLoad Semiconductor Tap Changer for Small Power Transformer," J, Applied Sci., Vol. 5, pp. 999-1003, 2005

[16] Eng Kian Kenneth Sng, S. S. Choi and D. Mahinda Vilathgamuwa," Analysis of Series Compensation and DC-Link Voltage Controls of a Transformerless Self-Charging Dynamic Voltage Restorer," IEEE Trans. on power delivery, Vol. 19, No. 3, JULY 2004

\section{APPENDIX}

\section{The System Parameters}

\section{Static load}

$\begin{array}{lll}\mathrm{R}_{\mathrm{L}} & \text { load resistance } & =35 \Omega \\ \mathrm{L}_{\mathrm{L}} & \text { load inductance } & =0.155 \mathrm{H} \\ \mathrm{R}_{\mathrm{S}} & \text { supply resistance } & =5 \Omega \\ \mathrm{L}_{\mathrm{S}} & \text { supply inductance } & =0.05 \mathrm{H} \\ \mathrm{C} & \text { max value of controlled capacitance }=20 \mu \mathrm{f}\end{array}$

\section{Dynamic load (ac series motor)}

$\begin{array}{lll}\mathrm{R}_{\mathrm{m}} & \text { motor resistance } & =10.5 \Omega \\ \mathrm{L}_{\mathrm{m}} & \text { motor inductance } & =0.11783 \mathrm{mH} \\ \mathrm{J} & \text { motor inertia constant } & =0.0015 \mathrm{Kg} \cdot \mathrm{m}^{2} \\ \mathrm{~B} & \text { motor frication coefficient }=0.00001 \mathrm{Nm} / \mathrm{rad} / \mathrm{s} \\ \mathrm{n} & \text { rated motor speed } & =3000 \mathrm{rpm} \\ \mathrm{V} & \text { rated motor voltage } & =220 \mathrm{volt} \\ \mathrm{P} & \text { rated motor power } & =1 / 3 \mathrm{hp} \\ \mathrm{I} & \text { rated motor current } & =1.9 \mathrm{~A}\end{array}$

